\title{
MEMÓRIAS PROFISSIONAIS
}

\section{Déa Ribeiro Fenelon \\ Pontifícia Universidade Católica de São Paulo}

(...) sempre me orientei por uma opção de que a prática de formação de profissionais da História deveria ser a expressão constante de uma experiência social vivenciada. Foi ai que busquei a inspiração e a força para levar à frente uma prática profissional, seja em sala de aula, seja na academia, na produção de conhecimento ou nas associações, nas discussões às vezes tediosas, às vezes inflamadas, sobre as direçôes a seguir em se tratando da formação de nossos profissionais de História - sempre com a devida consciência de cidadania e de responsabilidade social para com o presente e o futuro.

(Déa Fenelon, 2006)

Inicialmente, quero dizer da minha satisfação em estar neste Encontro de Pesquisadores de Ensino de História ${ }^{1}$ e agradecer o convite aos organizadores, em especial às professoras Lana e Cláudia Ricci, para participar desta mesa-redonda com velhos amigos e também fazer novos, o que estas oportunidades sempre proporcionam. Encaro este como mais um momento de diálogo, que sempre enfrentei com muito gosto, desde o começo de minha carreira profissional - dispondo-me sempre a praticálo, em qualquer espaço ou instância. Hoje, estou aqui com pesquisadores que estão na luta cotidiana da vida acadêmica e que partilham interesses comuns.

Como profissional de História, sempre me preocupei com as questões do ensino e aqueles que me conhecem sabem das lutas, dos conflitos pelas posições assumidas, das incompreensões enfrentadas ao longo de tantos anos. Não estou só apontando agravos ou agruras, mas acredito que, durante estes anos, acompanhei passo a passo toda esta discussão, os impasses, os desentendimentos, as opções e os avanços deste campo. Devo admitir que, nos últimos anos, os afazeres de orientações de dissertações e teses, de mestrandos e doutorandos, aulas de pós-graduação e participação em projetos de pesquisa, além do cansaço natural de anos de trabalho, me afastaram bastante do dia-a-dia das questões relacionadas ao ensino de História. Por certo, havia também as divergências sobre os rumos e os espaços que tomavam as reuniões e as articulações sobre os fóruns associativos, mas me mantive informada, acompanhando o desenrolar das discussões e dos debates. 
Por tudo isso, quero esclarecer que não me aterei especificamente ao tema proposto, mas penso apresentar mais uma reflexão sobre as diferentes formas de discuti-lo, usando minhas experiências e vivências, tratando-as como memórias profissionais, para discutir, principalmente, a questão de como abordamos Tempo e História em nossas atividades, pesquisas, práticas docentes, etc. Uma merecida aposentadoria e o avanço dos anos me qualificam para esta reflexão, que quero partilhar com todos vocês, aqui e agora.

Considerei relevante, na mesa-redonda de ontem, nas falas das professoras Ernesta Zamboni, da FAE/Unicamp, e Cláudia Ricci, da FAE/UFMG, a identificação da década de 1980 como momento do despertar e do surgimento de interesse maior pela necessidade de pesquisas sobre o ensino de História. Quero introduzir mais um ingrediente que me parece também ter grande importância na aceleração desse debate: o surgimento, em vários estados, a partir das Secretarias Estaduais de Educação, das chamadas Propostas Curriculares para o ensino de História de 1o e 20 graus. A virada da política desses órgãos, da existência dos famosos Guias Curriculares, acompanhados de Cadernos de Textos indicados por especialistas, para a idéia de "Propostas Curriculares", a serem discutidas com os professores da rede pública, pensadas como o encaminhamento de sugestões e orientações, tinha essa intenção e significou, sem dúvida, um avanço, ainda que momentâneo, nas práticas oficiais da política educacional - o que ocorreu pelo menos no nível do estado de São Paulo, em órgãos como a CENP. Causou imensa polêmica, mas conseguiu mobilizar a Rede Estadual de São Paulo e de outros estados, levando a discussão, inclusive, não apenas para o âmbito das Associações Científicas, mas também para a APEOESP, em São Paulo, e o Sind-UTE/ MG, etc.

Algumas teses de mestrado trabalharam a questão, mas o assunto ficou esquecido, voltando-se à forma antiga, e continuamos apenas criticando. Daí sugerir, não sei se seria interessante, organizar pesquisas por vários outros estados e regiões sobre o assunto, considerando possibilidades de exploração nas brechas das várias administrações estaduais e muni-cipais.

Está ainda bem viva em minha memória a última discussão em que me empenhei - a da construção das Diretrizes Curriculares para os Cursos de História, realizadas no âmbito da PUC-SP e dos Encontros Regionais e Simpósios da ANPUH. Do meu ponto de vista e considerando inúmeras outras experiências, creio que avançamos bastante, embora reconheça que, 
na prática da elaboração e da discussão das Reformas Curriculares dos Cursos de História, oportunidades foram perdidas, posições defensivas prevaleceram e nossa criatividade para reinventar o que gostaríamos que fosse uma grade curricular que correspondesse às expectativas se mostrou pequena e acanhada..., além de envolvida por receios e dificuldades de enfrentar o novo e a mudança ou o inevitável receio do desemprego.

Em um dos Diagnósticos e Avaliação sobre os cursos de História no Brasil, realizados pela SESU, no período de 1981-84, cujo Relatório Final foi publicado em 1986, participei como membro e Coordenadora do Grupo de Consultores. Nossa maior frustração foi que, apesar de realizar enquetes, entrevistas, enviar questionários a todas as coordenações de curso e departamentos de História, patrocinar discussões e mesas-redondas em encontros regionais e simpósios da ANPUH, ao final, o resultado que nos decepcionou foi o pequeno grau de mobilização conseguido e a ausência quase total de propostas alternativas para o enfrentamento das questões e dos problemas identificados. A justificativa de todos se exprimia na dificuldade imposta pela camisa-deforça de um currículo mínimo definido em lei que chegava até a especificação de disciplinas. Basta reler as Conclusões Finais e as propostas apresentadas para reavivar o caminho percorrido desde aquela década, com resultados bastante positivos.

É certo que avançamos, mas, agora, quando se superou esta barreira e se rompeu a especificação, infelizmente, a maioria de nossos cursos de História não soube ou não quis aproveitar a oportunidade e, de certa maneira, eles continuaram, em maior ou menor escala, presos a concepções antigas de seriação cronológico-espacial, surgindo como novidade a requentada proposta de inclusão da História da África, que afinal agora se torna obrigatória por decreto. Não posso dizer que conheço todas as reformulações curriculares, mas, sobre aquelas que acompanhei, pode-se bem refletir a respeito de grandes declarações teóricometodológicas, sendo que, na prática, essas são anuladas por disputas menores, defesa de território, recusa em enfrentar a virada necessária e possível, resultando, às vezes, em acomodações esdrúxulas e sem coerência com os pressupostos anunciados.

Rememoro tudo isso um pouco porque, como já assinalei, estou em fase de reflexões sobre o caminho percorrido e também para reafirmar minha satisfação em participar deste Encontro, sobretudo ao examinar mais detidamente a programação e, ainda mais, o conjunto das comunicações e relatos que serão aqui apresentados nos Grupos de Trabalho. 
Posso garantir o quanto me animou perceber o grau de consolidação alcançado nestes eixos de preocupações teóricas e metodológicas que constituem, sobretudo, o elenco de pesquisas, trabalhos de titulação e práticas docentes realizados em todos os cantos do país e que agora pretendem a expansão internacional, trazendo convidados de outros países para dialogar e discutir possibilidades de cooperação e entrosamento.

Falar da contribuição que essas pesquisas vêm dando à melhoria do ensino, como define um dos objetivos deste Encontro, seria insistir no óbvio, pois somente o interesse que despertam já comprova esta premissa. Quero, entretanto, avançando nesta reflexão, assinalar uma questão bastante discutida na mesa-redonda de ontem. Gostaria de falar da necessidade de maior divulgação, não apenas no meio acadêmico, mas também da necessidade de caminhar na direção de extravasar fronteiras, romper barreiras de editoras, tentar a edição de coletâneas, ocupar os espaços em inúmeros periódicos da área, inventar e criar opções para além do âmbito dos Encontros, Seminários ou Reuniões como esta que aqui acontece. Parece que o caminho das atividades propostas pelos Laboratórios de Ensino estão a apontar para uma opção acertada e eficiente. Se não nos dedicarmos a essas tarefas, corremos o risco de permanecermos falando somente para nós mesmos ou fechados no circulo de especialistas que se fecham sobre si mesmos ou, pior ainda, nos contentarmos com o enriquecimento teórico-metodológico de nossas pesquisas, o crescimento de nossos eixos temáticos e a consolidação dos Programas de PósGraduação e de todos os Grupos de Pesquisa credenciados nas diversas Agências de Fomento à Pesquisa.

Isso também se aplicaria às inúmeras dissertações e teses com temáticas de interesse pertinente às nossas preocupações e defendidas nos vários Programas de Pós-Graduação e que permanecem apenas referendadas nos Catálogos oficiais ou nas Bibliotecas Universitárias. Deixo essa questão como um ponto para o debate. Por que, na prática, nós, historiadores e pesquisadores sobre o ensino de História, estamos tão afastados do que acontece em outras áreas que também lidam com a questão da Educação? (Isso para não falar de nosso distanciamento da sociedade ou do social, que sempre dizemos ser nosso objeto, nossa matéria e nossa área profissional?). É claro que esta não é uma questão só nossa, mas um pouco mais geral, nos remetendo ao distanciamento entre o ensino, a escola, a universidade e a sociedade em que vivemos.

Nessa direção e propondo mais uma questão para o debate, creio também que as pesquisas e as discussões sobre os livros didáticos, seu 
conteúdo, sua autoria e sua atualização didática precisam avançar um pouco mais no terreno do domínio e das exigências das editoras, bem como dos critérios de escolha e recomendação dos órgãos oficiais e suas comissões. Não nos esquecendo que essas comissões são formadas por nossos pares, pesquisadores e professores como nós. Certamente esses pontos estão a exigir de nós mais atenção e aprofundamento nas pesquisas. Quase sempre deixamos muito disso para trás e nos limitamos a estabelecer uma relação crítica com o livro em si mesmo, sem considerá-lo em seu contexto de produção e na formação profissional de seus autores e de suas propostas, ou mesmo o porquê de sua aceitação e indicação pelas comissões oficiais.

Outro ponto para nossa reflexão e que, afinal, acompanhou-nos como preocupação dominante se refere à formação do professor de História, que, como vimos no mapeamento apresentado ontem, representa um forte contingente de pesquisas. Desde algumas indagações e investigações sobre o desempenho de alunos em questões discursivas do vestibular, minha atenção se voltou para a questão: Quem foram os professores de História desses alunos? Como foi que aprenderam esta História? E, como conseqüência inevitável: Qual foi a formação que tiveram esses profissionais? O que recairia sobre os cursos de História e sobre os formadores de profissionais para o ensino e a pesquisa. O cerne desta discussão, que, posso afirmar, não é fácil, enfrenta, às vezes, resistências ferozes. Creio ser este um dos principais "nós" de nosso debate, pois sabemos se tratar de uma questão complexa. No entanto, não quero, de maneira alguma, perder o fio da meada, pois creio ser este um ponto essencial, se queremos realizar mudanças.

Neste assunto, sempre me orientei pela opção de que esta prática de formação de profissionais da História deveria ser a expressão constante de uma experiência social vivenciada. Foi aí que busquei a inspiração e a força para levar à frente uma prática profissional, seja em sala de aula, seja academia, na produção de conhecimento ou nas associações, nas discussões às vezes tediosas, às vezes inflamadas, sobre as direções a seguir em se tratando da formação de nossos profissionais de História - sempre com a devida consciência de cidadania e de responsabilidade social para com o presente e o futuro. Para ser coerente na insistência que tenho mantido de repensar nossa relação com o passado e a História a partir do presente, devo reafirmar que, se queremos ser e formar historiadores comprometidos com o social, nosso campo de atuação será sempre este, ou seja, estaremos interessados em voltar aos acontecimentos do passado 
não apenas para conhecer e enriquecer nossa cultura geral, mas para desvendar as razões que o engendraram, buscando transformar o presente, sempre atentando para o que nele resta do passado. Por isso mesmo, estaremos sempre nos perguntando como e porquê aconteceu desta maneira, e não de outra. Quando assim nos posicionamos, queremos questionar temáticas, periodizações, relevâncias e hegemonias construídas, por exemplo, pela manipulação da Memória.

No entanto, mais do que trabalhar novos temas e novas abordagens, trata-se de propô-los de forma a (re)afirmar a contemporaneidade e a vitalidade crítica da reflexão, entendendo que a operação histórica requer um movimento não só retrospectivo, mas, fundamentalmente, prospectivo, sempre colocando em causa as relações entre Tempo, Memória e História, que é o nosso tema hoje.

Como qualquer experiência humana, a memória é também um campo minado pelas lutas sociais, campo de luta política, de verdades que se batem, no qual os esforços de ocultação e de clarificação estão presentes na disputa entre sujeitos históricos diversos, produtores de diferentes versões, interpretações, valores e práticas culturais. A memória histórica constitui uma das formas mais poderosas e sutis de dominação e legitimação do poder. Reconhecemos que tem sido sempre o poder estabelecido que definiu, ao longo do tempo histórico, quais memórias e quais histórias deveriam ser consideradas para que fosse possível estabelecer uma "certa" memória capaz de cunhar uma História "certa".

Não há aqui nenhuma intenção de tornar essas abordagens como formas absolutas e únicas de produzir o conhecimento histórico. Estou falando, todo o tempo, do imenso campo de possibilidades que há no social para ser explorado, investigado, reescrito, redimensionado e, sobretudo, ensinado, para que outros sujeitos possam ocupar o lugar que lhes pertence no campo da História deste país. Nuances específicas, discussões matizadas, estas são e serão sempre apresentadas e referenciadas às matrizes teóricas com as quais nos identificamos. Falo, pois, com certeza e, para chamar a atenção de quantos me ouvem, que interesses de investigação serão sempre conduzidos a partir de concepções e de supostos que vão servir de referência ao nosso trabalho e que sempre haverá inúmeras abordagens a serem investigadas, trabalhadas, debatidas, comparadas, etc. Queremos, pois, produzir e fazer História com o compromisso social de dar visibilidade a outros sujeitos até aqui excluídos, para que possam recuperar seu lugar na História, reavivando suas memórias, suas lembranças e narrativas, para podermos construir outras histórias em que 
pessoas se reconheçam, uma História que lhes diga algo ou com a qual passem a se identificar.

Estou partindo, pois, do reconhecimento da diversidade, da pluralidade, do direito de batalhar pela construção de projetos alternativos e, por isso mesmo, vou reafirmando que, para mim, a História será sempre política porque comprometida com o seu tempo, o tempo presente.

Nesta direção, lembro aqui o envolvimento de vários professores da PUC-SP e alguns de seus orientandos, que, no ano 2000, se dispuseram a apresentar ao Programa de Cooperação Acadêmica da CAPES um projeto que chamamos de Cultura, Trabalho e Cidade: Muitas Memórias Outras Histórias, que se dispunha, em cooperação com a PósGraduação da Universidade Federal de Uberlândia, a Unesp/Assis História e a Universidade Católica de Salvador, a realizar uma série de atividades que carregavam muito das perspectivas a que me referi e que durou quatro anos. Foi um trabalho bastante frutífero, pois realizamos vários seminários, cursos, etc., que proporcionaram ocasiões bastante ricas de discutir e tentar avançar em nossas propostas, concretizando os objetivos de uma real Cooperação Acadêmica. Deste trabalho, resultou uma publicação bastante rica de artigos sobre pesquisas realizadas dentro dos pressupostos alinhavados por nós. ${ }^{2}$

Politizar o ofício do historiador transcende em muito a preocupação com novos temas, problemas e abordagens. Construir um olhar político implica, para o historiador, colocar-se no presente com autonomia, crítica e, portanto, como protagonista. O que significa, conforme propõe Beatriz Sarlo $(1997)^{3}$, fazer da história uma autobiografia, supondo ainda a avaliação constante do próprio percurso e o reconhecimento da responsabilidade histórica de cada um. $\mathrm{Na}$ realidade brasileira atual, diante do consenso neoliberal que estabelece a desigualdade como paradigma do relacionamento social e da organização da dominação, politizar o debate supõe repensar os pactos e os esquecimentos, evitando que, em nome da conciliação nacional, sejam igualados os dois lados. Fazer uma história autobiográfica é, pois, indagar sobre o papel dos intelectuais no processo de construção da unidade político-ideológica, da versão autorizada dos acontecimentos e de sua contrapartida: a produção da invisibilidade e da inaudibilidade dos dissidentes pelo apagamento dos sinais e vestígios de suas memórias e histórias. Como argumenta Sarlo, trata-se de aceitar o desafio de ser capaz de dotar as memórias evocadas com a mesma força do esquecimento.

Ainda na trilha de Sarlo, ao refletir sobre a relação da História com o passado a partir do presente, endossamos suas proposições, segun- 
do as quais é importante colocar as dissidências em foco, o traço oposicionista frente aos discursos estabelecidos, aguçar a percepção das diferenças, entendendo-as como alternativas em relação às linhas da tradição e da inércia, descobrindo, assim, as fissuras no que estava consolidado, as rupturas que podem indicar mudanças, e permitindo o aprofundamento da investigação. E, ainda, o olhar político sobre nossos objetos não se dedica a organizar um paradigma, mas se mantém atento às tendências que questionam e subvertem a ordem estabelecida, pois está sempre pronto a descobrir e relacionar, consciente de sua historicidade. Resta sublinhar que, nesse caso, a autonomia não implica o afastamento da política e nem as sujeição ao seu jogo.

Dito isso, vivo a me questionar e percebo sinais semelhantes em muito da produção e da pesquisa sobre o ensino: por que não se consegue reverter a idéia ou a imagem predominante de que há uma História acontecida e ela, como tal, deve ser ensinada? Ainda que se aceite a diversidade de abordagens e a possibilidade de construir outras visões de História, com todas essas premissas, por que não conseguimos traduzir isso em nosso ensino de História e em nossa prática docente?

Belo Horizonte, fevereiro de 2006.

\section{NOTAS}

${ }^{1}$ Texto inédito apresentado na mesa-redonda "Memória, Tempo e História: perspectivas teóricas e metodológicas para a pesquisa em ensino de História", realizada no VII Encontro Nacional de Pesquisadores do Ensino de História, em Belo Horizonte, na Faculdade de Educação da UFMG, em fevereiro de 2004. Buscou-se manter a linguagem coloquial da apresentação original, introduzindo-se apenas modificações que adequassem o texto ao registro escrito e a uma publicação acadêmica.

${ }^{2}$ FENELON, Déa (Org.). Muitas memórias, outras histórias. São Paulo: Olho dágua, 2004.

${ }^{3}$ SARLO, Beatriz. Paisagens imaginárias. São Paulo: Edusp, 1997.

Recebido: $21 / 04 / 08$

Aprovado: 30/04/08

Contato:

E-mail: regina.helena@gmail.com 